\title{
EFEKTIFITAS JERUK NIPIS (CITRUS AURANTIFOLIA) DALAM MEMATIKAN LARVA NYAMUK ANOPHELES SP
}

\author{
Fajar Akbar, Zrimurti Mappau, Fitriani S \\ Jurusan Kesehatan Lingkungan Poltekkes Kemenkes Mamuju
}

\begin{abstract}
Anopheles $S p$ mosquitoes around the world contain about 2000 species, while those that can transmit malaria are about 60 species. According to observations in Indonesia found 80 species Anopheles $\mathrm{Sp}$, while the vector malaria is 22 species with different breeding places. This study aims to determine the effectiveness of leaf, skin, and lemon juice on the death of Anopheles Sp larvae. This study is an experimental study to determine the effectiveness of lime in deadly mosquito larvae Anopheles Sp. The samples used in this research are Anopheles Sp instar III and IV mosquito larvae. This test is done every 3 times for 6 hours and observed every 1 hour. The results of this study showed that lime by comparing leaf, skin, and lime juice for 6 hours with 20 Anopheles $S p$ mosquito larvae in each experiment showed that using lemon leaf solution the highest number of deaths on 6 hours observation 16,7 tail $(83,5 \%)$, lemon peel solution highest average death rate at 6 hours observation as much as 19,3 tails (96,5\%), and lime juice the average number of death highest at 6 hours of observation of 19 tails (95\%). Based on the research results, it can be concluded that lime is able to kill Anopheles $S p$ mosquito larvae with effective comparison is lime skin with percentage of death of $96 \%$. Should approach the community and socialize the potential of natural resources, in this case the use of lime as a natural larvacide to reduce the number of larval populations and can be applied as a method of overcoming malaria and can develop penilitian utilization of lime.
\end{abstract}

Keywords: Anopheles sp larvae, lime, death

\section{PENDAHULUAN}

Penduduk di Indonesia rawan terkena malaria sekitar $50 \%$, terutama di daerah pedesaan dan antara masyarakat miskin. Daerah paling rawan malaria terletak di luar Jawa, terutama daerah timur Indonesia, dari Nusa Tenggara Timur ke Maluku dan Papua. Daerah Sumatera, Kalimantan dan Sulawesi mempunyai tingkat transmisi malaria sedang. Jakarta dan Bali mempunyai tingkat penyebaran malaria antara nol sampai rendah (Mandagi Chreisye, 2011). Lokasi penularan penyakit tular vektor ditentukan oleh tipe topografi serta keberadaan vektor yang dapat beradaptasi dengan lingkungan maupun pola hidup masyarakat. Berdasarkan lokasi penularan penyakit yang ditularkan nyamuk Anopheles $S p$ perlu diperhatikan beberapa aspek yaitu, ketinggian tempat, letak geografis, susunan geologi, dan luas wilayah (Kemenkes, 2012).

Wilayah endemis malaria di Sulawesi Barat pada umumnya adalah desa terpencil dengan kondisi lingkungan yang tidak baik, sarana transportasi dan komunikasi yang sulit, akses pelayanan kesehatan kurang, tingkat pendidikan dan sosial ekonomi masyarakat yang rendah. Sulawesi Barat pada tahun 2010 menderita penyakit malaria adalah $6,7 \%$, mengalami penurunun menjadi $5,9 \%$ pada tahun 2011 dan pada tahun 2012 menjadi 2,6 $\%$. Kabupaten yang termasuk dalam daerah endemis malaria cukup tinggi yakni Mamuju dan Mamuju Utara. Kondisi wilayah yang ada, menjadi salah satu faktor tingginya kasus malaria di kedua wilayah tersebut dibandingkan dengan wilayah lain (Sulbar, 2013).

Jeruk nipis adalah salah satu bahan alternatif yang dapat digunakan untuk mengurangi larva Anopheles $S p$ karena mengandung senyawa limonoida (Jiaxing Li 2001 dalam Utariningsih 2010) dalam menggantikan larvasida kimia yang merupakan salah satu cara mengurangi populasi larva Anopheles Sp. Buah jeruk nipis selain kaya vitamin dan mineral juga mengandung zat bioflavonoid yang berguna untuk mencegah terjadinya pendarahan pada pembuluh nadi, kemunduran mental dan fisik, serta mengurangi luka memar. Disamping itu sari buah jeruk nipis mengandung asam sitrat $7 \%$ dan minyak atsiri "limonen" (Agustin M. A., 2015). Senyawa yang terkandung dalam daun jeruk nipis adalah Senyawa limonoida yang merupakan teranoriterpen yang terdapat dalam daun jeruk nipis yang berguna sebagai antifeedant terhadap serangga, zat pengatur 
tumbuh dan zat toksik pada kutu beras, larvasida, anti mikroba, penolak serangga (repellent) dan penghambat reproduksi (Jiaxing, Li, 2001 dalam Utariningsih, 2010).

Upaya untuk mencegah meningkatnya populasi nyamuk Anopheles $S p$ yang merupakan vektor penyakit malaria, dilakukan pemutusan mata rantai perkembangan nyamuk malaria yaitu melalui pengendalian larva nyamuk Anopheles Sp. Salah satu cara pengendalian larva nyamuk Anopheles $S p$ adalah dengan melakukan penambahan daun, kulit, dan buah jeruk nipis. Selain itu juga bisa mengurangi daun, kulit dan buah jeruk nipis tersebut yang telah menjadi sampah.

Larva nyamuk Anopheles Sp pada umumnya ditemukan atau tumbuh kembangnya terdapat di rawa, empang, sawah, serta terdapat di lingkungan yang tidak sehat, kurang bersih, dan perubahan cuaca dan iklim. Penggunaan larvasida kimia memiliki dampak negatif dan berbahaya yang sangat besar di antaranya pencemaran lingkungan, membunuh hewan peliharaan, kematian predator dan menyebabkan penyakit yang berbahaya pada manusia. Berdasarkan hasil penelitian menunujukkan bahwa dari 50 jentik sampel yang diberikan perlakuan diperoleh pada percobaan pertama sebesar 32 ekor jentik mati, percobaan kedua dengan 34 ekor jentik mati dan percobaan ketiga dengan 34 ekor jentik yang mati. Rata-rata tingkat mortalitas sebesar 67\% terhadap larva Aedes Spp, bahan yang digunakan terdapat di alam yaitu jeruk nipis yang efektif membunuh larva (Prijadi, 2013).

Jeruk nipis mudah di peroleh di daerah mana saja. Jeruk nipis selain bisa di jadikan bahan tambahan makanan juga bisa di jadikan obat yang berkhasiat. Jeruk nipis mampu membunuh larva karena mengandung bahan beracun yang disebut limonoida, serta dapat mengurangi sampah yang bersumber dari jeruk nipis (Ningrum, 2004). Maka dari itu penulis melakukan penelitian dengan menggunakan buah jeruk nipis dengan perbandingan antara daun, kulit, dan perasan buah jeruk nipis dan efektif membunuh larva Anopheles Sp instar III dan IV.

\section{BAHAN DAN METODE}

\section{Jenis dan Desain Penelitian}

Penelitian ini termasuk dalam penelitian kuantitatif dengan desain eksperimen yaitu menguji efektifitas daun jeruk, buah dan kulit jeruk nipis yang nantinya diujikan sebagai larvasida alami terhadap larva nyamuk Anopheles Sp.

\section{Lokasi dan Waktu Penelitian}

Penelitian ini dilaksanakan di Laboratorium Poltekkes Kemenkes Mamuju Jalan Poros Mamuju Kalukku Km.16 Tadui Sulawesi Barat. Waktu penelitian yang dilaksanakan yaitu pada Bulan April - Mei 2016.

\section{Objek Penelitian}

Objek penelitian ini adalah larva Anopheles Sp instar III dan IV yang dipaparkan larutan daun, kulit jeruk nipis dan perasan buah jeruk nipis serta kontrol yang diberi perlakuan yang sama yaitu 20 larva Anopheles sp. Air perasan daun, kulit dan buah jeruk nipis sebanyak $10 \mathrm{ml}$ dimasukkan ke dalam botol sampel yang telah diisi larva 20 ekor.

Pengujian akan dilakukan sebanyak 3 kali sehingga jumlah sampel yang digunakan sebanyak 240 ekor larva untuk mengamati setiap perlakuan yang ada. Pengamatan akan berlangsung selama 6 jam dan diamati setiap 1 jam.

\section{HASIL}

Berdasarkan hasil penelitian yang dilakukan di Laboratorium Poltekkes Kemenkes Mamuju diperoleh hasil pengamatan selama 6 jam pada larutan daun jeruk, kulit jeruk dan perasan buah jeruk nipis sebagai berikut :

Berdasarkan tabel 1. diketahui bahwa kematian larva nyamuk Anopheles Sp instar III dan IV dengan perlakuan menggunakan larutan daun jeruk nipis sebanyak $10 \mathrm{ml}$ selama 6 jam yaitu rata-rata kematian tertinggi yaitu 5 $(30,1 \%)$ pada jam ke 3 dan rata-rata kematian terendah adalah 1,3 $(7,8 \%)$ pada jam ke 5 .

Berdasarkan tabel 2. dapat diketahui bahwa kematian larva nyamuk Anopheles $S p$ instar III dan IV dengan perlakuan menggunakan larutan kulit jeruk nipis sebanyak $10 \mathrm{ml}$ selama 6 jam yaitu rata-rata kematian tertinggi yaitu $9(46,6 \%)$ pada jam ke 2 dan rata-rata kematian terendah yaitu $1 \quad(5,2 \%)$ pada jam ke 6 .

Berdasarkan tabel 3. dapat diketahui bahwa kematian larva nyamuk Anopheles sp instar III dan IV dengan perlakuan menggunakan perasan buah jeruk nipis sebanyak $10 \mathrm{ml}$ selama 6 jam dan mengukur $\mathrm{pH}$ 
yaitu rata-rata kematian tertinggi yaitu 11,3 $(60,1 \%)$ pada jam pertama dan rata-rata kematian terendah yaitu 0 pada jam ke 5 .

Tabel 1. Distribusi Kematian Larva Nyamuk Anopheles Sp sebanyak 20 ekor dengan Pengujian Menggunakan Larutan Daun Jeruk Nipis Sebanyak $10 \mathrm{ml}$ Selama 6 jam

\begin{tabular}{ccccccc}
\hline \multirow{2}{*}{$\begin{array}{c}\text { Waktu } \\
\text { (Jam) }\end{array}$} & $\begin{array}{c}\text { Kontrol } \\
\text { (Jumlah } \\
\text { mati) }\end{array}$ & $\begin{array}{c}\text { I } \\
\text { (Jumlah } \\
\text { mati) }\end{array}$ & $\begin{array}{c}\text { II } \\
\text { (Jumlah } \\
\text { mati) }\end{array}$ & $\begin{array}{c}\text { III } \\
\text { (Jumlah } \\
\text { mati) }\end{array}$ & $\begin{array}{c}\text { Nilai } \\
\text { rata-rata } \\
\text { kematian }\end{array}$ & $\begin{array}{c}\text { Persentase } \\
\text { kematian } \\
(\%)\end{array}$ \\
\hline 1 & 0 & 1 & 2 & 3 & 2 & 12,1 \\
2 & 0 & 3 & 9 & 0 & 4 & 24,1 \\
3 & 0 & 8 & 4 & 3 & 5 & 30,1 \\
4 & 0 & 2 & 3 & 1 & 2 & 12,1 \\
5 & 0 & 4 & 0 & 0 & 1,3 & 7,8 \\
6 & 0 & 1 & 1 & 5 & 2,3 & 13,8 \\
\hline \multicolumn{2}{c}{ Total } & 19 & 19 & 12 & 16,6 & 100 \\
\hline
\end{tabular}

Tabel 2. Distribusi Kematian Larva Nyamuk Anopheles Sp Sebanyak 20 ekor dengan Pengujian Menggunakan Larutan Kulit Jeruk Nipis Sebanyak 10 ml Selama 6 jam

\begin{tabular}{|c|c|c|c|c|c|c|}
\hline \multirow[b]{2}{*}{$\begin{array}{l}\text { Waktu } \\
\text { (Jam) }\end{array}$} & \multicolumn{4}{|c|}{ Perlakuan } & \multirow[b]{2}{*}{$\begin{array}{l}\text { Nilai rata-rata } \\
\text { kematian }\end{array}$} & \multirow[b]{2}{*}{$\begin{array}{c}\text { Persentase } \\
\text { kematian } \\
(\%)\end{array}$} \\
\hline & $\begin{array}{c}\text { Kontrol } \\
\text { (Jumlah } \\
\text { mati) }\end{array}$ & $\begin{array}{c}\text { I } \\
\text { (Jumlah } \\
\text { mati) }\end{array}$ & $\begin{array}{c}\text { II } \\
\text { (Jumlah } \\
\text { mati) }\end{array}$ & $\begin{array}{c}\text { III } \\
\text { (Jumlah } \\
\text { mati) }\end{array}$ & & \\
\hline 1 & 0 & 0 & 6 & 7 & 4,3 & 22,3 \\
\hline 2 & 0 & 3 & 14 & 10 & 9 & 46,6 \\
\hline 3 & 0 & 2 & - & 3 & 1,7 & 8,8 \\
\hline 4 & 0 & 4 & - & - & 1,3 & 6,7 \\
\hline 5 & 0 & 6 & - & - & 2 & 10,3 \\
\hline 6 & 0 & 3 & - & - & 1 & 5,2 \\
\hline \multicolumn{2}{|c|}{ Total } & 18 & 20 & 20 & 19,3 & 100 \\
\hline
\end{tabular}

\section{PEMBAHASAN}

\section{Efektifitas Daun Jeruk Nipis}

Berdasarkan perlakuan selama 6 jam dengan menggunakan larutan daun jeruk nipis sebanyak $10 \mathrm{ml}$ pada larva nyamuk Anopheles $S p$ instar III dan IV terhadap kematian hewan uji diketahui bahwa terdapat larva yang mati dengan perlakuan sebanyak 3 kali dan nilai total rata-rata larva yang mati sebanyak 16,6 dan persentasenya yaitu $83 \%$. Kandungan bahan aktif pada daun jeruk nipis yang memberikan efek larvasida yaitu limonoid yang bekerja menghambat pergantian kulit pada larva nyamuk. Limonoid adalah salah satu jenis senyawa yang bersifat racun. Sebagai racun perut limonoid dapat masuk ke dalam tubuh larva nyamuk. Masuk ke pencernaan melalui rendaman larutan yang termakan sehingga masuk ke organ pencernaan dan di serap oleh dinding usus kemudian beredar bersama darah yang akan mengganggu metabolisme tubuh nyamuk sehingga akan kekurangan energi untuk aktifitas hidupnya yang akan mengakibatkan kejang dan akhirnya mati (Gunawan, 2004).

Pada perlakuan pertama dengan menggunakan larutan daun jeruk nipis sebanyak $10 \mathrm{ml}$ jumlah kematian larva sebanyak 19 ekor selama 6 jam, untuk perlakuan kedua jumlah larva yang mati sebanyak 19 ekor selama 6 jam, dan untuk perlakuan ketiga jumlah larva yang mati sebanyak 12 ekor selama 6 jam. Untuk 
media kontrol yang tidak diberi penambahan larutan daun jeruk nipis $10 \mathrm{ml}$ tidak terdapat larva Anopheles $S p$ yang mati selama waktu perlakuan. Sehingga nilai rata-rata kematian larva Anopheles $S p$ dengan menggunakan larutan daun jeruk nipis $10 \mathrm{ml}$ selama 6 jam adalah sebanyak $16,6(83 \%)$.

Tabel 3. Distribusi Kematian Larva Nyamuk Anopheles Sp Sebanyak 20 ekor dengan Pengujian Menggunakan Perasan Buah Jeruk Nipis Sebanyak 10 ml Selama 6 jam

\begin{tabular}{|c|c|c|c|c|c|c|}
\hline \multirow[b]{2}{*}{$\begin{array}{c}\text { Waktu } \\
\text { (Jam) }\end{array}$} & \multicolumn{4}{|c|}{ Perlakuan } & \multirow[b]{2}{*}{$\begin{array}{l}\text { Nilai rata- } \\
\text { rata } \\
\text { kematian }\end{array}$} & \multirow[b]{2}{*}{$\begin{array}{c}\text { Persentase } \\
\text { kematian } \\
(\%)\end{array}$} \\
\hline & $\begin{array}{c}\text { Kontrol } \\
\text { (Jumlah } \\
\text { mati) }\end{array}$ & $\begin{array}{c}\text { I } \\
\text { (Jumlah } \\
\text { mati) } \mathrm{pH} \mathrm{3,4}\end{array}$ & $\begin{array}{c}\text { II } \\
\text { (Jumlah } \\
\text { mati) pH 2,2 }\end{array}$ & $\begin{array}{c}\text { III } \\
\text { (Jumlah } \\
\text { mati) } \mathrm{pH} \mathrm{2,6}\end{array}$ & & \\
\hline 1 & 0 & 20 & 10 & 4 & 11,3 & 60,1 \\
\hline 2 & 0 & - & 2 & 2 & 1,3 & 6,9 \\
\hline 3 & 0 & - & 2 & 3 & 1,6 & 8,5 \\
\hline 4 & 0 & - & 5 & 4 & 3 & 16 \\
\hline 5 & 0 & - & 0 & 0 & 0 & 0 \\
\hline 6 & 0 & - & 1 & 4 & 1,6 & 8,5 \\
\hline \multicolumn{2}{|c|}{ Total } & 20 & 20 & 17 & 18,8 & 100 \\
\hline
\end{tabular}

Penggunaan ekstrak daun jeruk nipis dengan dosis yaitu $100 \mathrm{mg}$ per 1 liter air yang digunakan peneliti sebelumnya (Prijadi, 2013), menyatakan bahwa ekstrak daun jeruk nipis mampu membunuh larva Aedes Spp instar III. Sedangkan pada penelitian oleh Rina Murdani (2014) menggunakan ekstrak daun jeruk nipis dengan berbagai konsentrasi menyatakan bahwa pada konsentrasi terkecil mampu membunuh larva Aedes aegypti instar III.

\section{Efektifitas Kulit Jeruk Nipis}

Berdasarkan perlakuan selama 6 jam dengan menggunakan larutan kulit jeruk nipis sebanyak $10 \mathrm{ml}$ pada larva Anopheles Sp instar III dan IV terhadap kematian hewan uji diketahui bahwa terdapat larva yang mati dengan perlakuan sebanyak 3 kali dan nilai total rata-rata larva yang mati sebanyak 19,2 dan persentasenya yaitu $96 \%$. Tanaman jeruk nipis digunakan sebagai biolarvasida karena mengandung senyawa limonoida. Limonoida merupakan senyawa aktif alam penting yang terdiri atas komponen triterpenoid teroksidasi. Pada tanaman jeruk, limonoid diproduksi pada daun dan ditransfer ke buah dan bij. Dalam daun dan buah, kandungan total limonoid meningkat selama masa pertumbuhan (Devy et al, 2010).

Racun pada buah jeruk merupakan racun perut limonoid dapat masuk ke dalam tubuh larva melalui pencernaan dan di serap oleh dinding usus kemudian beredar bersama darah yang akan mengganggu metabolisme tubuh sehingga dapat menyebabkan kematian terhadap larva. Pada perlakuan pertama dengan menggunakan larutan kulit jeruk nipis sebanyak $10 \mathrm{ml}$ jumlah kematian larva sebanyak 18 ekor selama 6 jam, untuk perlakuan kedua jumlah larva yang mati sebanyak 20 ekor selama 6 jam, dan untuk perlakuan ketiga jumlah larva yang mati sebanyak 20 ekor selama 6 jam. Untuk media kontrol yang tidak diberi penambahan larutan kulit jeruk nipis $10 \mathrm{ml}$ tidak terdapat larva Anopheles Sp yang mati selama waktu perlakuan. Sehingga nilai rata-rata kematian larva Anopheles $S p$ dengan menggunakan larutan kulit jeruk nipis $10 \mathrm{ml}$ selama 6 jam adalah sebanyak 19,2 (96\%).

Berdasarkan penggunaan minyak atsiri kulit jeruk nipis (Citrus aurantifolia $\mathrm{S}$ ) dengan berbagai konsentrasi dan menggunakan abate sebagai kontrol positif serta aquades sebagai kontrol negatif yang di gunakan peneliti sebelumnya oleh Lia Diana (2013) menyatakan bahwa minyak atsiri kulit jeruk nipis (Citrus aurantifolia S) mampu membunuh larva Aedes aegypti instar III.

\section{Efektifitas Perasan Buah Jeruk Nipis}

Berdasarkan perlakuan selama 6 jam dengan menggunakan perasan buah jeruk nipis sebanyak $10 \mathrm{ml}$ pada larva Anopheles Sp instar 
III dan IV pada kematian hewan uji diketahui bahwa terdapat larva yang mati dengan perlakuan sebanyak 3 kali dan nilai total ratarata larva yang mati sebanyak 18,8 dan persentasenya yaitu 94\%. Pada perlakuan pertama dengan menggunakan perasan buah jeruk nipis sebanyak $10 \mathrm{ml}$ jumlah kematian larva sebanyak 20 ekor selama 6 jam, untuk perlakuan kedua jumlah larva yang mati sebanyak 20 ekor selama 6 jam, dan untuk perlakuan ketiga jumlah larva yang mati sebanyak 17 ekor selama 6 jam. Untuk media kontrol yang tidak diberi penambahan perasan buah jeruk nipis $10 \mathrm{ml}$ tidak terdapat larva Anopheles $S p$ yang mati selama waktu perlakuan. Sehingga nilai rata-rata kematian larva Anopheles $S p$ dengan menggunakan perasan bauh jeruk nipis $10 \mathrm{ml}$ selama 6 jam adalah sebanyak 18,8 (94\%).

Pada pengujian menggunakan perasan buah jeruk nipis yang mengandung senyawa beracun (limonoida) dan melakukan pengukuran $\mathrm{PH}$ dapat membunuh larva Anopheles Sp. Pada perlakuan pertama jumlah kematian larva nyamuk Anopheles $S p$ sebanyak 20 ekor dengan $\mathrm{pH} 3,4$, sedangkan pada perlakuan kedua jumlah larva nyamuk Anopheles Sp yang mati sebanyak 20 ekor dengan $\mathrm{pH} 2,2$, dan pada perlakuan ketiga jumlah larva nyamuk Anopheles $S p$ sebanyak 17 ekor dengan $\mathrm{pH} 2,6$. Hal ini menunjukkan bahwa semakin rendahnya $\mathrm{pH}$ maka dapat mempengaruhi kehidupan larva, karena larva masih dapat berkembang dan hidup pada kisaran pH antara 4-11 (Clark, 2004)

Dalam pengujian menggunakan larutan daun, kulit dan perasan buah jeruk nipis dalam mematikan larva naymuk Anopheles $S p$, hal ini menunjukkan bahwa penggunaan larutan kulit jeruk nipis sebanyak $10 \mathrm{ml}$ lebih efektif mematikan larva Anopheles Sp dibanding daun jeruk nipis dan perasan buah jeruk nipis. Berdasarkan penelitian sebelumnya dengan menggunakan ekstrak daun jeruk nipis yang dilakukan pada hewan uji larva Aedes spp instar III dengan dosis yang digunakan yaitu $100 \mathrm{mg}$ per 1 liter air dinyatakan efektif (Jiaxing, Li 2001 dalam (Utariningsih, 2010).

\section{KESIMPULAN DAN SARAN}

Berdasarkan hasil penelitian dan analisa yang telah dilakukan, maka dapat disimpulkan sesuai dengan tujuan yang akan dicapai dalam penelitian ini adalah sebagai berikut: Larutan daun jeruk nipis sebanyak $10 \mathrm{ml}$ efektif membunuh larva nyamuk Anopheles Sp selama 6 jam sebanyak 83\%. Larutan kulit jeruk nipis sebanyak $10 \mathrm{ml}$ efektif membunuh larva nyamuk Anopheles Sp selama 6 jam sebanyak 96\%. Perasan buah jeruk nipis sebanyak $10 \mathrm{ml}$ efektif membunuh larva nyamuk Anopheles $S p$ selama 6 jam sebanyak $94 \%$.

\section{DAFTAR PUSTAKA}

Agustin, M. A. (2015). Pengaruh Berkumur Larutan Ekstrak Jeruk Nifis 40\% terhadap Pertumbuhan Bakteri Streptococcus Muntas pada Saliva Anak yang Mengalami Karies Dini (Early Childhood Caries). Makassar: Fakultas Kedokteran Gigi Unhas.

Clark, e. a. (2004). pH tolerances and regulatory abilities of freshwater and euryhaline aidine larvae. http://rudyct. com/PPs702-ipb/07134/atmowidi.

Gunawan. (2004). Ilmu obat alam (Farmakognosi) (jilid 1 ed.). Jakarta.

Kemenkes. (2012). Jumlah kasus malaria di Indonesia. Jakarta: Direktorat Jenderal Pengendalian Penyakit dan Penyehatan Lingkungan.

Mandagi Chreisye, R. P. (2011). Analisis bionomik nyamuk anopheles di Desa Ranoketaktua Kec. Amurang Kab. Minahasa Selatan. Jurnal FKM Universitas Sam Ratulangi.

Ningrum, W. (2004). Aktivitas anti bakteri minyak atsiri kulit buah jeruk nipis terhadap bakteri S.aerus dan E.Coli.

Prijadi, d. (2013). Uji efktivitas ekstrak daun jeruk nipis (Citrus aurantifolia) dalam menghambat pertumbuhan larva Aedes spp. Jurnal FKM Sam Ratulangi Manado.

Sulbar, D. (2013). Profil Kesehatan Sulbar Maтuju . Mamuju: Dinas Kesehatan Provinsi Sulbar.

Utariningsih, D. (2010). Pemanfaatan Daun Jeruk Nipis (Citrus aurantifolin) sebagai larvasida untuk pemberantasan nyamuk aedes aegypti. http://contents/index. ac.id.com manfaat-daun-jeruk-nipis. 